\title{
O Destino da Razão em uma Era de Pós-Verdade: Reflexões a Partir de O Futuro De Uma Ilusão de Sigmund Freud
}

\author{
Marcelo da Costa Maciel \\ (Universidade Federal Rural do Rio de Janeiro, Brasil)
}

\section{Resumo}

Este ensaio reflete sobre as atuais condições de produção e difusão do conhecimento na área das Humanidades, explorando também as perspectivas que se abrem para o futuro. Tomando como ponto de partida O Futuro de uma llusão, avalia-se, à luz da contemporaneidade, o diagnóstico feito por Freud acerca da era moderna e do lugar nela desempenhado pela religião e pela ciência. Em seguida, discute-se o conceito de "pósverdade" como uma chave-interpretativa para a compreensão da época atual, ressaltando-se suas implicações sobre o campo das Humanidades. Nesse ponto, são abordados temas tais como a crise da razão, o declínio das Humanidades e o império das tecnologias. Por fim, o artigo pretende apontar algumas possibilidades abertas para o ensino e a pesquisa nas Humanidades. Seguindo a reflexão feita por Max Weber em A Ciência como Vocação (1917), ressalta-se a necessidade da dedicação obstinada e da entrega apaixonada, sem otimismo exagerado, mas também sem resignação ou renúncia. Como conclusão, o artigo apresenta o ofício de professor e pesquisador das Humanidades como o ofício de um guardador e transmissor de um patrimônio extremamente valioso no presente e que poderá, mesmo, ser indispensável no futuro.

Palavra-chave: Modernidade. Crise da razão. Pós-verdade. Futuro das Humanidades.

\begin{abstract}
This essay intends to examine the current conditions of production and diffusion of knowledge in the field of the Humanities, also exploring the prospects that may be opened for the future. Taking as a starting-point Sigmund Freud's statements in the essay The Future of an Illusion (1927), we evaluate Freud's diagnosis of the modern era and the roles played by religion and science in it. Next, the concept of "post-truth" is discussed as a key for the understanding of the present time, highlighting its implications on the field of the Humanities. At this point, themes such as the crisis of reason, the decline of the Humanities and the empire of technologies are adressed. Finally, the paper intends to point out some possibilities for teaching and research in the Humanities nowadays. Following Max Weber's ideas in Science as Vocation (1917), the need for both enthusiasm and discipline, without exaggerated optimism, but also without resignation or renunciation, is emphasized. As a conclusion, we argue that professors and researchers in the Humanities are charged with the task of keeping and transmitting a heirloom that is extremely valuable at present and may even be indispensable in the future.
\end{abstract}

Keywords: Modernity. Crisis of reason. Post-truth. Future directions in the Humanities. 


\section{Introdução}

Este artigo consiste na tentativa de realizar uma primeira abordagem de um tema, sem nenhuma pretensão de esgotá-lo aqui. Ele traz uma reflexão sobre o nosso presente e o nosso futuro, e julgo não ser possível ter um conhecimento seguro acerca de fenômenos novos e ainda em curso, e muito menos acerca de seus possíveis desenvolvimentos futuros. Meu principal objetivo é compartilhar minhas impressões e minhas apostas: impressões baseadas na minha própria experiência e apostas resultantes de uma longa reflexão sobre essa experiência. Tais impressões e apostas surgiram das minhas inquietações com relação ao presente e ao futuro do conhecimento acadêmico no campo das Humanidades, especialmente com relação ao ofício do professor universitário.

Primeiramente, pretendo expor as questões que serviram de ponto de partida para a reflexão que desejo fazer aqui. Essas questões estão contidas no ensaio $O$ Futuro de uma llusão, escrito por Sigmund Freud em 1927. Todavia, não pretendo, de forma alguma, realizar uma análise da obra citada, sendo Freud um pensador com o qual não tenho muita familiaridade.

Após a colocação das questões que constituem o meu ponto de partida, vou esclarecer o que entendo por uma "era de pós-verdade". Adianto que me apropriei desta expressão simplesmente por considerar que ela designa de modo adequado o que penso. Não pretendo realizar aqui uma discussão teórica sobre a condição essencial do mundo contemporâneo nem sobre a nomenclatura que se deve empregar para exprimi-la: modernidade tardia, modernidade líquida, pós-modernidade, etc. Não sou um especialista no tema e, por isso, não entrarei na discussão

Ágora Filosófica, Recife, v. 21, n. 1, p. 198-208, jan./abr., 2021 • 199 
acerca do conceito de "pós-verdade", mas simplesmente utilizarei a expressão de uma forma muito despretensiosa, quase espontânea. Considero-a útil por sintetizar um certo diagnóstico de nosso momento atual e, particularmente, por sublinhar as dificuldades que acompanham a tarefa de ensinar algo aos jovens de hoje.

Por fim, na terceira e mais especulativa parte deste artigo, levantarei algumas possibilidades concernentes ao "destino da razão". Será exatamente nesse momento que minhas impressões darão lugar a uma aposta. Utilizo o termo "aposta" porque o que pretendo dizer acerca do futuro não vem acompanhado de nenhuma dose de fatalismo ou necessidade, nem mesmo de probabilidade. Trata-se de um futuro possível, mas que não está, de forma alguma, garantido. Pelo contrário, tal futuro parece, hoje, muito improvável. Todavia, não se trata de algo impossível. Esse futuro poderá, talvez, concretizar-se, mas isso dependerá de uma decisão e de uma ação realizadas hoje. Ele dependerá, particularmente, da decisão e da ação das pessoas que têm por ofício o ensino e a pesquisa no terreno das Humanidades.

\section{Ideias Centrais de Freud em O Futuro de uma Ilusão}

Neste ensaio Freud desenvolve uma reflexão sobre a origem e o futuro da religião. Ele argumenta que existe uma diferença entre "erro" e "ilusão", sendo a "ilusão" uma espécie de engano que vem ao encontro de um desejo ou necessidade nossa.

De acordo com Freud, a religião não é um "erro", mas sim uma forma de "ilusão". E a "ilusão religiosa" aproxima-se do conceito de "delírio" por não possuir valor de verdade. A religião fornece refúgio e proteção para um homem ainda infantil, não emancipado, que não pode 
suportar reconhecer a sua própria pequenez e a ausência de sentido no mundo. Por essa razão, Freud considera a religião "a neurose obsessiva universal da humanidade". (FREUD, 2010a, p. 67).

No ensaio O Mal-Estar na Cultura, escrito em 1929, Freud retoma a discussão acerca da essência da religiosidade e rejeita a opinião de Romain Rolland, segundo a qual a origem da religião se encontraria em uma espécie de "sentimento oceânico", visto como uma reação humana supostamente universal produzida pela ideia do eterno (IBIDEM, 2010b, p. 42). Para Freud, tal sentimento não é universal (ele próprio não reconhecia qualquer vestígio disso nele) e, mesmo que alguém o tivesse, isso não condiziria necessariamente a um apego a ideias religiosas. As crenças religiosas derivariam, na verdade, de uma certa reação ao sentimento da pequenez e da impotência humanas diante do todo do mundo, mais especificamente, da tentativa infantil de obter auxílio diante de tal sentimento.

Voltando ao ensaio O Futuro de uma Ilusão, nele Freud afirma: "Quem se conforma humildemente com o papel insignificante do homem na vastidão do mundo, é antes irreligioso no mais verdadeiro sentido da palavra". (IBIDEM, 2010a, p. 54). Nesta obra, Freud prevê o gradual desaparecimento da religião. Para ele, a religião seria suplantada à medida que a ciência se desenvolvesse e se tornasse a verdadeira base da civilização humana. Todavia, até o presente momento, o proclamado desaparecimento da religião, de fato, não ocorreu, nem tampouco o desenvolvimento da ciência conduziu a uma civilização indubitavelmente mais feliz.

Não é preciso aqui citar os diversos pensadores (de Rousseau a Nietzsche) que perceberam um potencial 
autodestrutivo no projeto de construção de uma civilização da razão. Pretendo, todavia, deter-me em uma consequência da modernidade que não foi enfatizada por seus críticos, mas que, hoje, parece tornar-se cada vez mais patente.

Há uma faceta inesperada e contraditória no projeto da modernidade, e somos levados a reconhecer que estamos, de fato, em uma era totalmente nova, que rompeu radicalmente com os fundamentos que sustentavam a era anterior. Se podemos falar em "pósmodernidade", a característica mais marcante dessa situação é que ela consiste em uma era de "pós-verdade". Porém...

\section{Que é uma "era de Pós-Verdade"?}

Trata-se de uma era em que a verdade deixou de ser um valor fundamental. E parece que essa perda do valor da verdade é uma consequência inevitável da própria autorreflexividade da modernidade. Uma certa decepção com relação aos resultados a que conduziu a busca racional da verdade é responsável, hoje, por um enfraquecimento da disposição para essa busca. Quando a própria ideia de verdade cai em descrédito, constatamos uma espécie de exaustão do projeto de conhecimento da verdade: Por que buscar tal conhecimento? Seria ele possível? Teria ele alguma utilidade? Ele poderia tornar nossa vida melhor? E o patrimônio de conhecimentos acumulados desde os Antigos: teria ele alguma importância hoje?

O conhecimento almejado pelos Antigos e pelos Modernos visava discernir entre diferentes discursos, julgando sua legitimidade, de modo a estabelecer o discurso verdadeiro, aquele capaz de orientar nossas 
vidas. Mas, hoje, qual discurso é capaz de orientar uma ação consistente consigo mesma? Quando o próprio valor da verdade se esvai, os discursos parecem nivelar-se e bombardeiam-nos com uma velocidade estonteante. Existiria algum discurso mais crível? No mundo das "fake news" e da proliferação instantânea e descontrolada de informações, parece não haver lugar para aquilo que os

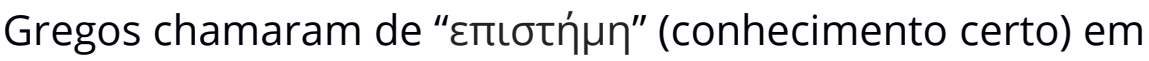

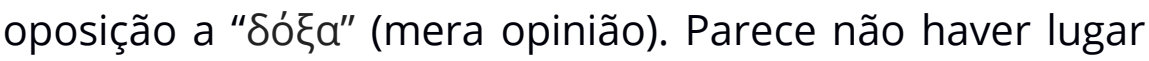
sequer para o exercício do pensamento.

Talvez nada disso seja novo. Mas parece que realmente novo é o fato de que estamos diante de uma geração que já nasceu nessa fase avançada da pósmodernidade. Aqueles que, hoje, têm entre dezoito e vinte e cinco anos, muito provavelmente, não experimentam o tempo presente como um tempo de mudanças macrohistóricas. Talvez, para eles, não haja sentido na história de que o homem, em um determinado momento de um passado já longínquo, ousou empregar a sua faculdade racional para pensar e construir o próprio mundo humano. Talvez não haja sentido em reconstituir, para eles, as incontáveis discordâncias que emergiram a partir daquele momento, isto é, em narrar a história humana como uma incessante sucessão de mundos possíveis construídos pelo pensamento. Nem talvez haja sentido em ressaltar que, apesar das discordâncias, algo esteve sempre presente: a expectativa com relação ao conhecimento buscado, um autêntico interesse por um tipo de conhecimento que pode ser expresso por diferentes nomes: filosofia, ciência, verdade, etc.

Então, a pergunta que se impõe é esta: Como ser professor dessa nova geração? Já os Gregos Antigos levantaram a questão sobre a possibilidade de se ensinar

Ágora Filosófica, Recife, v. 21, n. 1, p. 198-208, jan./abr., 2021 • 203 
e aprender algo. Hoje, as perguntas devem ser: Existe alguém interessado em discutir se há ou não algum conhecimento? Existe alguém disposto a dedicar o seu tempo a essa questão, que foi crucial para inúmeras gerações passadas? A ciência, independentemente de uma possível aplicabilidade técnica, teria algum significado nos dias de hoje?

Não preciso aqui repetir as palavras de Martin Heidegger, no texto Serenidade, para ressaltar os perigos da perda de sentido da busca pelo saber (HEIDEGGER, 2000). Renunciando ao pensamento que medita, corremos o risco de nos tornarmos meros executores do pensamento que só calcula e, assim, deixarmos de ser sujeitos de nosso próprio mundo para sermos conduzidos por um avanço inexorável sobre o qual não podemos mais pensar, julgar, avaliar.

$\mathrm{Na}$ visão de Freud, o progresso faria com que o "deus da religião" fosse substituído pelo "deus-logos" (FREUD, 2010a, p. 79). Mas, hoje, temo que esse "deuslogos" tenha se emancipado e se transfigurado em "deustecnologia", "deus-poder" ou "deus-dinheiro". Nesse ponto, gostaria de trazer para esta reflexão as perguntas fundamentais levantadas por Max Weber em A Ciência como Vocação, texto escrito dez anos antes do texto de Freud (WEBER, 1982). As perguntas são:

\section{4 “O Que Devemos Fazer? Como Devemos Viver?”}

Weber pronunciou essas perguntas diante de uma plateia de estudantes da Universidade de Munique e, mais de cem anos depois, repito essas mesmas perguntas, com o mesmo tom angustiado. E ouso apontar para a mesma atitude de Weber diante dessa angústia: nem desespero, nem resignação, nem fuga individualista, nem otimismo 
entusiasta, mas a atitude de manter acesa uma tênue e incerta chama de esperança e dedicar-se incansavelmente ao trabalho cotidiano, mesmo que tal esforço pareça já não ter nenhum sentido. Em resumo, a atitude de Weber conjuga, paradoxalmente, incerteza e aposta.

Ele realizou uma análise realista de seu tempo e identificou tendências, aparentemente férreas, que determinariam o futuro. Mas, ao mesmo tempo, reconheceu a possibilidade da emergência de uma reviravolta a partir de fatores imprevisíveis, bem como do retorno de ideias, valores e concepções que, aparentemente, estavam sepultadas para sempre. Em sua obra mais famosa, A Ética protestante e o Espírito do Capitalismo, Weber disse:

Ninguém sabe ainda a quem caberá no futuro viver nessa prisão, ou se, no fim desse tremendo desenvolvimento, não surgirão profetas inteiramente novos, ou um vigoroso renascimento de velhos pensamentos e ideias, ou ainda se nenhuma dessas duas. (1989, p. 86).

A propósito, podemos recordar aqui certas mudanças ocorridas na história intelectual do Ocidente que contrariaram as expectativas e que foram provocadas pelo retorno daquilo que havia caído em descrédito, mas que havia sido, de alguma forma, preservado. Por exemplo:

- O retorno do pensamento de Aristóteles ao Ocidente graças ao trabalho de preservação, tradução e comentário de filósofos árabes, como Avicena e Averróis. 
- O renovado interesse pela cultura grecoromana no contexto do Renascimento.

- O impacto do reaparecimento dos textos dos Céticos Antigos sobre a crise da Filosofia Escolástica e a formação da Filosofia Moderna.

Não podemos descartar a possibilidade de que um novo Renascimento volte a ocorrer, em algum momento, na história dos homens. Por que acreditar que essa história chegou ao seu fim, à sua consumação? Talvez não vejamos nenhuma mudança produzida por um possível resgate da importância de um saber aparentemente ultrapassado. Mas, talvez, isso possa ocorrer daqui a cem ou duzentos anos. Temos de considerar que esta é uma possibilidade em aberto. E para que continue sendo uma possibilidade em aberto, temos de continuar nosso trabalho cotidiano: o trabalho de guardadores $\mathrm{e}$ transmissores do patrimônio de saber que constitui o campo das Humanidades, uma herança de muito valor hoje em dia e que pode, mesmo, ser indispensável no futuro.

Este artigo termina com um clamor àqueles que trabalham no campo das Humanidades para não capitularem, mas exercerem uma nobre forma de resistência: a resistência intelectual das Humanidades. Independentemente de todas as nossas discordâncias acerca da verdade, o que nos une é o compromisso comum com a pesquisa da verdade e com a construção de um conhecimento que não é o conhecimento técnico, mas que é, como disse Sócrates, o conhecimento do homem e, como disse Aristóteles, o conhecimento do bem humano. 
Paradoxalmente, até para recusar essa proposta, teríamos de empregar o tipo de conhecimento ao qual me refiro aqui: o conhecimento filosófico ou meditante, pois citando novamente Aristóteles (um autor muito antigo, porém, mais do que nunca atual): "Se se deve filosofar, deve-se filosofar. Se não se deve filosofar, deve-se filosofar. De todos os modos, portanto, se deve filosofar". (ARISTÓTELES, Protréptico, fragmento 2).

\section{Referências}

ARISTÓTELES. Protrepticus or Exhortation to Philosophy. Edited and translated by D. S. Hutchinson and M. R. Johnson. Disponível em http://protrepticus.info. Acesso em: 23 mar 2018.

FREUD, S. O Futuro de uma llusão. Porto Alegre: L\&PM Editores, 2010a.

FREUD, S. O Mal-Estar na Cultura. Porto Alegre: L\&PM Editores, 2010b.

HEIDEGGER, M. Serenidade. Lisboa: Piaget, 2000.

WEBER, M. "A Ciência como Vocação". In: GERTH, H. H. e MILLS, C. W. (Orgs.). Ensaios de Sociologia. Rio de Janeiro: Guanabara, 1982.

WEBER, M. A Ética Protestante e o Espírito do Capitalismo. São Paulo: Pioneira, 1989.

Marcelo da Costa Maciel

Possui Graduação em Ciências Sociais pela Universidade Federal do Rio de Janeiro (1992), Mestrado em Sociologia pelo Instituto Universitário de Pesquisas do Rio de Janeiro (1994) e Doutorado em Ciência Política pelo Instituto Universitário de Pesquisas do Rio de Janeiro (2003). Atualmente, é Professor 
Associado I da Universidade Federal Rural do Rio de Janeiro, atuando nos Programas de Pós-Graduação em Filosofia e Ciências Sociais desta mesma instituição. Tem como principais campos de interesse: 1) Filosofia Moral e Política; 2) Ceticismo Antigo e Moderno; 3) Estudos sobre Max Weber; 4) Religião, Secularização e Política.

E-mail: marcelocmaciel@bol.com.br

Submetido: 11/05/2020 Aprovado: 17/08/2020 